\title{
DERIVATION OF FORCES ACTING ON THE LIQUID WELD METAL BASED ON ARC PRESSURE MEASUREMENTS PRODUCED USING ALTERNATING SHIELDING GASES IN THE GTAW PROCESS
}

\author{
S.W. Campbell ${ }^{1}$, A.M. Galloway ${ }^{1}$, N.A. McPherson ${ }^{2}$ \\ ${ }^{1}$ Dept. of Mechanical \& Aerospace Engineering, University of Strathclyde, Glasgow, UK \\ ${ }^{2}$ BAE Systems Surface Ships Limited, Glasgow, UK
}

GTAW, Alternating shielding gases, GTAW-P, Arc pressure, Arc forces, Fluid flow

\begin{abstract}
As part of an ongoing process to fully evaluate the effects of an alternating shielding gas supply on the gas tungsten arc and gas metal arc welding processes, a comparison between arc pressures produced using argon, helium, alternating gases and GTAW-P has been conducted.

The alternating shielding gas process is reported to create a dynamic stirring action within the liquid weld metal as a result of three independent phenomena: a) variation in weld pool fluidity, b) arc pressure variation, and c) arc pressure peaking. These effects have been the basis of previous advantages associated with the process, however these phenomena have not previously been verified and are based solely on theoretical assumptions.

Arc pressure measurements are presented which allowed for the numerical derivation of various forces acting on the liquid weld metal in order to estimate the flow vectors present when each shielding gas is present.
\end{abstract}

\section{List of Symbols}

Parc Arc pressure (stagnation pressure at anode) $\left(\mathrm{N} / \mathrm{m}^{2}\right)$,

$\rho g \quad$ Density of the shielding gas $\left(\mathrm{kg} / \mathrm{m}^{3}\right)$

$V \quad$ Velocity $(\mathrm{m} / \mathrm{s})$

$\tau p \quad$ Plasma shear stress $\left(\mathrm{N} / \mathrm{m}^{2}\right)$

Lp Dynamic viscosity of the arc plasma $(\mathrm{kg} /(\mathrm{m} . \mathrm{s}))$

$r \quad$ Distance in the radial direction (m)

Farc $\quad$ Arc force (N)

$R \quad$ Radius of arc (m)

$F_{L} \quad$ Lorentz force $\left(\mathrm{N} / \mathrm{m}^{3}\right)$

$J \quad$ Current density $\left(\mathrm{A} / \mathrm{m}^{2}\right)$

$B \quad$ Self-induced azimuthal magnetic field (N/(A.m))

$I \quad$ Current (A)

Ho Permeability of free space $\left(\mathrm{N} / \mathrm{A}^{2}\right)$

$F_{B} \quad$ Buoyancy force

$\rho_{w^{r}} \quad$ Density of the weld metal $\left(\mathrm{kg} / \mathrm{m}^{3}\right)$

g Gravity acceleration in the negative $\mathrm{z}$ direction $\left(\mathrm{m} / \mathrm{s}^{2}\right)$

$\boldsymbol{\beta} \quad$ Thermal expansion coefficient of the weld metal $(1 / \mathrm{K})$

$T \quad$ Local reference temperature (K)

$T_{\text {ref }} \quad$ Arbitrary reference temperature (melting temperature) (K)

Ma Marangoni number (dimensionless) 


$\begin{array}{ll}\delta \gamma / \delta T & \text { Temperature coefficient of surface tension }(\text { dyne } /(\mathrm{cm} . \mathrm{K})) \\ \Delta T & \text { Temperature difference between centre and edge of pool surface }(\mathrm{K}) \\ L & \text { Characteristic length (distance from weld centreline to fusion boundary) (mm) } \\ \mu_{w^{r}} & \text { Dynamic viscosity of the weld metal } \mathrm{g} /(\mathrm{cm} . \mathrm{s}) \\ \alpha & \text { Thermal diffusivity }\left(\mathrm{cm}^{2} / \mathrm{s}\right)\end{array}$

\section{Introduction}

Alternating shielding gases is a relatively new method of delivering the shielding gas to the weld region and involves the discrete delivery of two gases to the welding region in order to take advantage of the beneficial properties of each gas [1-6], with the added advantage of complex flow patters within the liquid weld metal.

To date, this has involved alternating between argon/argon based mixture and helium, and has been found to produce various benefits from both a technical and economic viewpoint. The use of alternating shielding gases has allowed for an increase in travel speed to be used whilst maintaining an equivalent weld geometry to the conventional shielding gas supply of argon or argon-helium mixtures [3-6], and subsequently resulted in a $17 \%$ cost reduction to the overall process [3]. In addition to the cost savings owing to the increased travel speed, a reduction in weld-induced distortion was also achieved due to the reduction in weld heat input [3-5]. The mechanical properties of the weld have been shown to be a function of the shielding gas delivery method [3,4]; improvements in the transverse and all-weld yield and tensile strength, Charpy impact toughness and ductility have been achieved, whilst a more uniform hardness through the weld, heat affected zone and parent plate was also found. Several studies have reported [1-4] that the alternating shielding gas process has resulted in a lower percentage of porosity in the solidified weld than conventional shielding gas mixtures. The benefits of using alternating shielding gases are linked to three independent phenomenon [1]: a) variation in arc pressure, $b$ ) arc pressure peaking and c) variation in weld pool fluidity, and are said to result in flow vectors opposite in direction for argon and helium [2].

Arc pressure measurements conducted when using argon have been published whilst investigating the effects of a variety of welding parameters including welding current [7-11], tungsten electrode geometry [10-12], arc length [10], nozzle outlet diameter [13] and shielding gas pressure [13]. The shielding gas composition is also known to have a considerable effect on the arc pressure $[9,10]$, however, the availability of data for helium and argon-helium mixtures is extremely limited and that for alternating shielding gases is non-existent.

A schematic diagram of the gas tungsten arc welding (GTAW) process, and the forces acting on the liquid weld metal are shown in Figure 1. Various forces acting on the liquid weld metal including arc force, plasma shear and Lorentz force can be derived numerically from the arc pressure distribution. In addition, the buoyancy force can also be determined numerically, whilst the surface tension gradient governs the Marangoni convection mode and can be estimated by the Marangoni number.

As with arc pressure data, publications for forces acting on the liquid weld metal focus on the use of argon as a shielding gas, with no data previously published for helium or argon-helium mixtures. The plasma shear stress is a result of the arc plasma moving radially outward creating a drag force on the liquid weld pool surface. Previous publications on plasma shear are based on numerical modelling techniques; Lee and $\mathrm{Na}$ [14] presented data for GTAW, whilst Hu and Tsai [15] simulated the gas metal arc welding (GMAW) process. The arc force is defined as the force of the arc plasma impinging on the weld pool surface; Burleigh and Eagar [16] measured the arc force using a torsion bar and displacement transducer, whilst Lin and Eagar [17] numerically integrated the arc pressure over the impingement area of the arc. The Lorentz (or 
electromagnetic) force is one of the driving forces for fluid flow [18-21] and is a result of the interaction between the current path in the weld pool and the magnetic field it generates; Kou and Wang [18] used computational modelling to show that the Lorentz force is the driving force for deeper penetration. Computational modelling generally considers the buoyancy force, caused by temperature gradients within the weld pool, and surface tension, caused by temperature gradients at the pool surface and is a function of surface active agents in the weld pool.
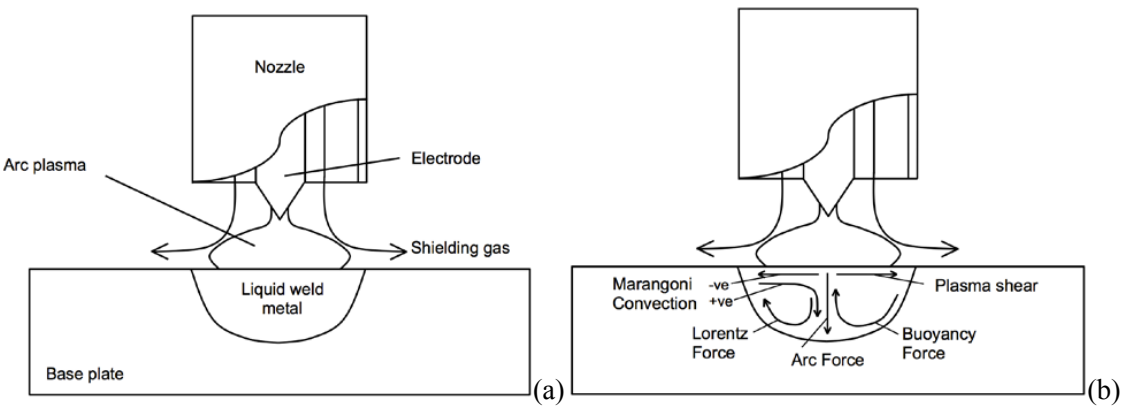

Figure 1: Schematic diagram of (a) GTAW process and (b) Forces acting on liquid weld metal

Kang et al. [2] presented Figure 2(a) for the transient variation of arc pressure, and Figure 2(b) for the flow vectors present when using alternating shielding gases based upon theoretical assumptions. However, no experimental or computational modelling has been provided to substantiate such assumptions.

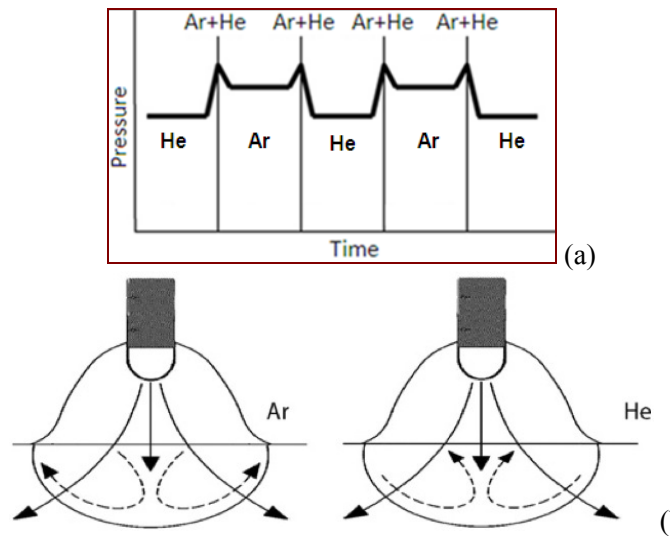

Figure 2: Schematic diagram showing the (a) variation of arc pressure, and (b) weld pool behaviour during alternating shielding gases [2]

A study [22] has therefore been conducted to generate arc pressure data when using the alternating shielding gas method, and compare the results with those generated for argon, helium and pulsed GTAW (GTAW-P). In addition, the arc pressure measurements will be used to 
determine the forces acting on the liquid weld metal [23] and evaluate the flow vector direction when each shielding gas is present.

\section{Experimental Setup}

All trials were performed using DC electrode negative (DCEN) with a welding current of $200 \mathrm{~A}$ on a $200 \times 150 \times 6 \mathrm{~mm}$ thick water-cooled copper plate. The experimental setup used for the measurement of arc pressure is shown in Figure 3, with a piezoelectric pressure sensor mounted beneath a $1 \mathrm{~mm}$ diameter hole in the centre of the plate. The voltage difference measured by the sensor was then converted to a real-time pressure reading using LabVIEW, with the arc pressure being recorded every $20 \mathrm{~ms}$.
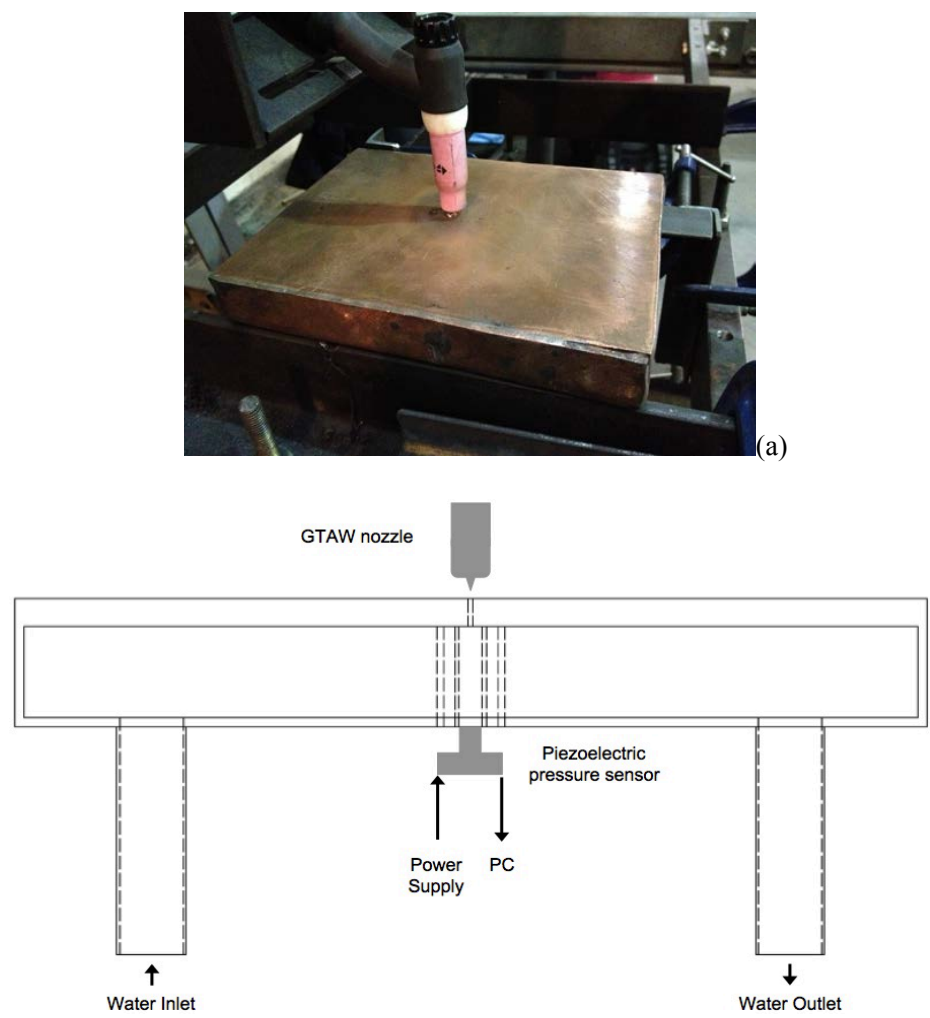

Figure 3: (a) Experimental setup, and (b) Schematic diagram showing location of piezoelectric pressure sensor.

Two shielding gas supplies were used throughout the trials, argon and helium. The flow of each gas was regulated by a dedicated electronic control unit (Figure 4), which supplies a signal to a solenoid valve on each gas line. The invert function allowed for alternating precision, the 
accuracy of the output frequency of $2 \mathrm{~Hz}$ being monitored using an oscilloscope. An average shielding gas flow rate of $10 \mathrm{l} / \mathrm{min}$ was used throughout.

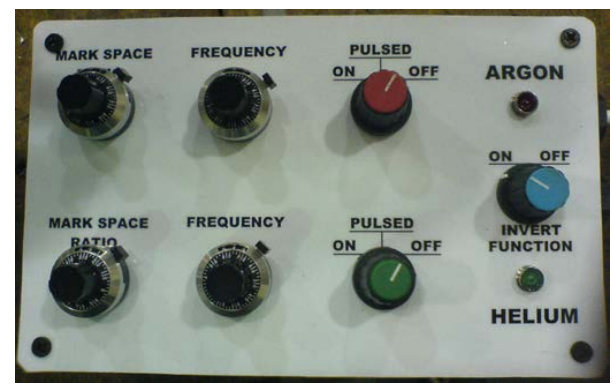

Figure 4: Electronic gas control unit

A $2.4 \mathrm{~mm}$ diameter, $2 \%$ thoriated tungsten electrode was used throughout, with a $45^{\circ}$ vertex angle and $2 \mathrm{~mm}$ arc length. GTAW-P trials were performed using a peak and background current of 200 and $100 \mathrm{~A}$ respectively, set at a frequency of $2 \mathrm{~Hz}$ to replicate the alternating shielding gas process.

\section{Results and Discussion}

Figure 5 shows the steady-state radial pressure distribution with respect to the arc centreline for argon and helium. As can be noted, the steady-state pressure produced by $\operatorname{argon}\left(\sim 1900 \mathrm{~N} / \mathrm{m}^{2}\right)$ at the arc centreline is considerably higher than that produced by helium $\left(\sim 800 \mathrm{~N} / \mathrm{m}^{2}\right)$. Figure 6 shows the transient pressure measurements at the arc centreline for argon and helium at arc initiation, which has highlighted that a considerable surge ( 25\%) occurs when the arc is struck, which takes approximately $3-5$ seconds to reach steady-state.

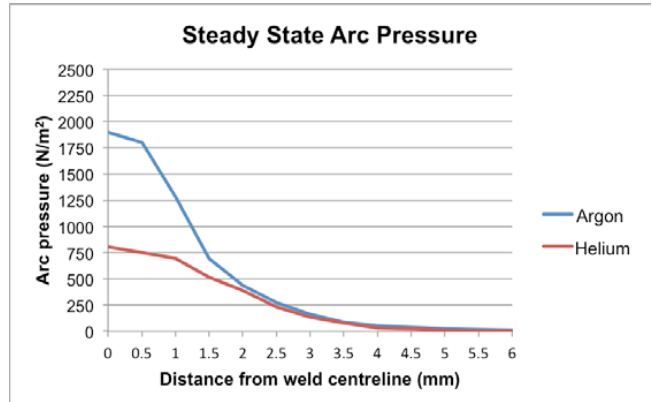

Figure 5: Steady-state arc pressure measurements 


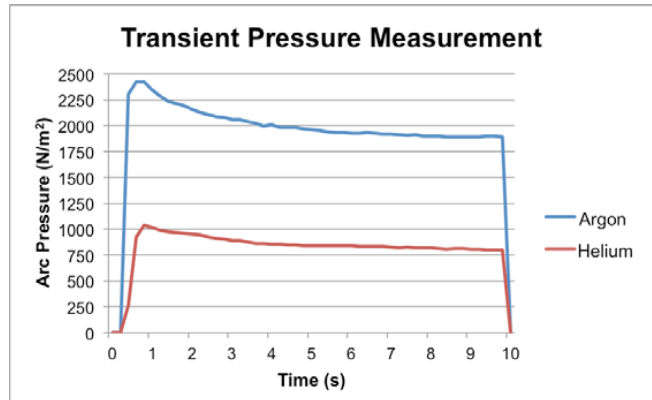

Figure 6: Transient arc pressure measurements at arc initiation

The transient arc pressure measurements at the arc centreline made whilst using alternating shielding and GTAW-P are shown in Figure 7. It can be noted that the alternating shielding gas process produces arc pressures comparable to those at arc initiation, whilst GTAW-P produces arc pressures comparable to the steady-state values. This can be attributed to the fact that during the alternating shielding gas process the arc is continually being re-established when each gas is present, whereas when using GTAW-P the power source is simply changing the magnitude of the current supply. As can be seen, the alternating shielding gas transient pressure measurements are considerably different to Figure 2(a) produced by Kang et al. [2]. Firstly, the alternating frequency of $2 \mathrm{~Hz}$ meant each gas was only supplied for 0.25 seconds before changing to the other gas, thus the entire time either gas is supplied is within the arc initiation pressure impulse and did not have sufficient time to reach steady-state. Secondly, the addition of helium to an argon-based mixture has been shown to considerably reduce the arc pressure [9], coupled with the fact that the shielding gas pressure has a negligible effect on the arc pressure [13] indicates that the 'spikes' shown between the 'steady-state' phases of Figure 2(a) should not exist. The non-deliberate intermixing of argon and helium between the welding unit and the welding torch has resulted in a 'smoothing' of the peak pressures. This 'smoothing' effect is not present in the GTAW-P process as the shielding gas is constant and the power supply change from peak to background currents is more instantaneous.

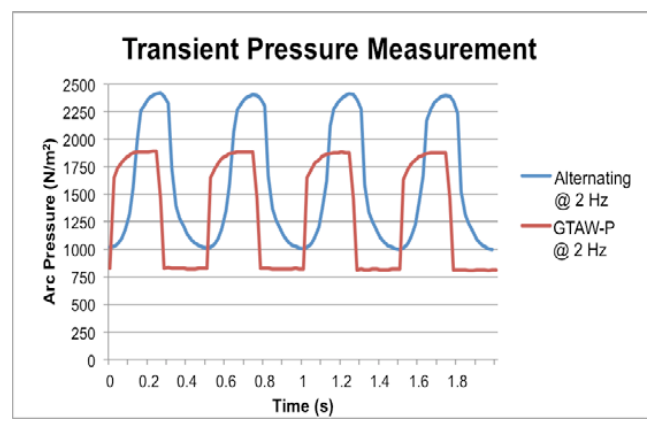

Figure 7: Transient arc pressure measurement during alternating shielding gases and GTAW-P 
The steady-state arc pressure distribution for argon and helium allows for various forces acting on the liquid weld metal to be evaluated, thus allowing for an estimation of the flow vectors present. Since the arc pressure is essentially the stagnation pressure of the plasma jet arrested at the anode plate surface, the axial velocity can be determined using Bernoulli's theorem:

$$
P_{a r c}=\frac{1}{2} \rho_{g} V^{2}
$$

The plasma shear stress causes the liquid weld metal to flow from the centre of the weld pool surface towards the pool boundary and return beneath the surface, and can be calculated using equation (2):

$$
\tau_{p}=\mu_{p} \frac{\delta v}{\delta r}
$$

The maximum shear stress was found to occur $1 \mathrm{~mm}$ from the arc centreline; and for argon and helium this was found to be $\sim 80 \mathrm{~N} / \mathrm{m}^{2}$ and $\sim 240 \mathrm{~N} / \mathrm{m}^{2}$ respectively. For argon, this was in agreement with data published by Lee and $\mathrm{Na}$ [14] and $\mathrm{Hu}$ and Tsai [15] for GTAW and GMAW respectively. The results show that helium produces a considerably larger plasma shear stress, thus encouraging the liquid weld metal to flow radially outwards at the weld pool surface.

The arc force was determined numerically by integrating the arc pressure over the impingement area of the arc in $0.0625 \mathrm{~mm}$ segments:

$$
F_{a r c}=\int_{0}^{R} 2 \pi r P_{a r c} d r
$$

The profile of the arc column when using argon and helium are shown in Figure 8. The effective arc diameter, i.e. the impingement diameter of the arc on the plate surface, was measured to be $7.5 \mathrm{~mm}$ and $6.5 \mathrm{~mm}$ for argon and helium respectively, using image analysis software.
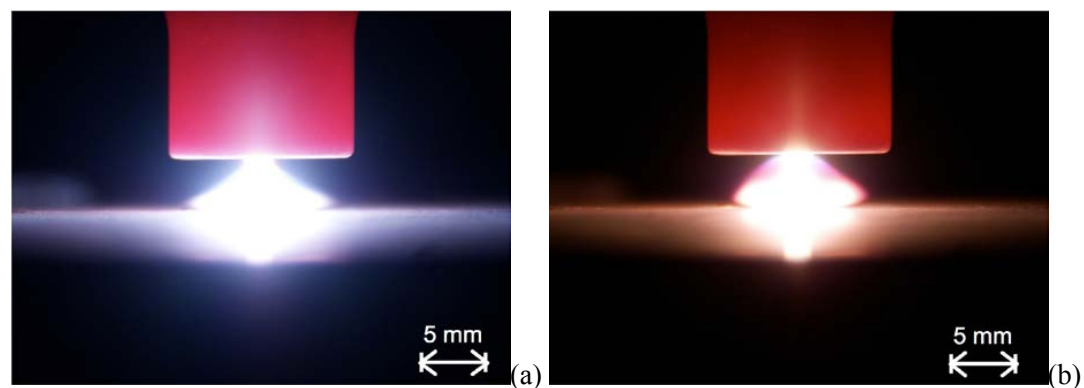

Figure 8: Arc profile produced using (a) argon, and (b) helium

The arc force was calculated to be $\sim 1800$ dyne and $\sim 1140$ dyne for argon and helium respectively. Lin and Eagar [10] presented Figure 9, a parabolic relationship between the arc force and the welding current for an argon shielding gas. As can be seen, the arc calculated for argon is in good agreement with this relationship as indicated on the graph. It can also be noted that the arc force generated by argon is approximately $60 \%$ greater than the corresponding value for helium. 


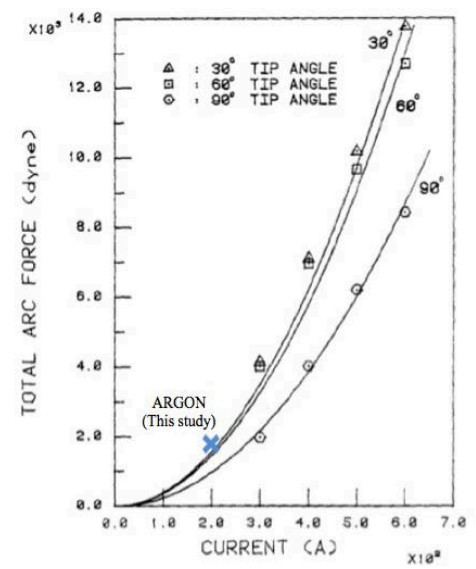

Figure 9: Arc force vs. welding current [10] showing argon arc force from present study

The Lorentz force can be calculated using:

$$
F_{L}=J B
$$

Where $J$, the current density, and $B$, the self-induced azimuthal magnetic field, can be derived using equation (5) and Ampere's equation (equation (6)) respectively:

$$
\begin{aligned}
& J=\frac{P_{\operatorname{arc}} I}{F_{a r c}} \\
& B=\frac{H_{0} O}{r} \int_{0}^{R} J r d r
\end{aligned}
$$

Combining equation (5) and (6) yields:

$$
B=\frac{u_{0} I}{2 \pi r}
$$

The Lorentz force distribution is shown in Figure 10; the Lorentz force is zero at the arc centreline since the self-induced magnetic field term tends to zero, as $r$ tends to zero. As with the arc force integration, calculations were performed over $0.0625 \mathrm{~mm}$ segments. The total Lorentz force was found to be approximately $60 \%$ greater for argon than helium, with forces of $5.08^{*} 10^{5} \mathrm{~N} / \mathrm{m}^{3}$ and $3.25^{*} 10^{5} \mathrm{~N} / \mathrm{m}^{3}$ respectively. 


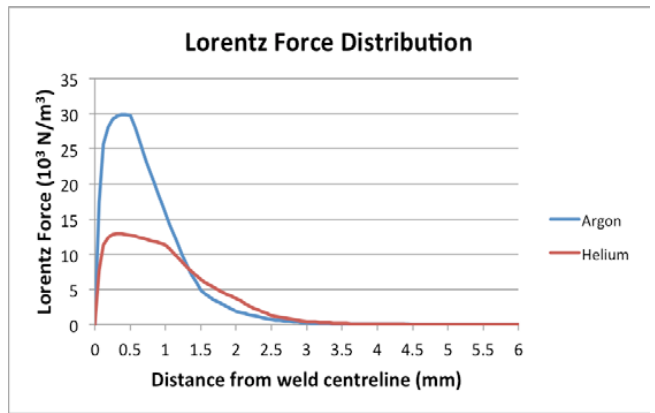

Figure 10: Lorentz force distribution

However, the distribution of the Lorentz force may be more significant; $<1.25 \mathrm{~mm}$ the Lorentz force for argon was approximately double that of helium, whereas $>1.25 \mathrm{~mm}$ to the edge of the arc helium produced a greater force.

The buoyancy force can be calculated using the Boussinesq approximation:

$$
F_{g}=-\rho_{w} g \beta\left(T-T_{r e f}\right)
$$

The magnitude of buoyancy force has been estimated based on data from other sources; Traidia and Roger [24] used computational modelling to determine a peak temperature in the GTAW weld pool of approximately $2350 \mathrm{~K}$ and $3700 \mathrm{~K}$ for argon and helium respectively, whilst Ley et al. [25] presented data for the linear thermal expansion of the weld metal in GMAW for argon and helium showing a maximum difference of $0.6^{*} 10^{-6} / \mathrm{K}$. This results in helium having a $\left(T-T_{r e f}\right)$ term in excess of three times greater than that of argon, whereas the thermal expansion coefficient term equates to only $4.6 \%$, thus it and the other terms are considered negligible in relation to the $\left(T-T_{r e f}\right)$ term. Therefore, the buoyancy force for helium can be estimated to be approximately three times that of argon.

The Marangoni number has been widely used to measure the extent of Marangoni convection and is given by:

$$
M a=\frac{\delta_{\gamma} / \delta T(\Delta T) L}{\mu_{w^{\alpha}}}
$$

Using values previously published for steel of negligible sulphur content, $\delta \gamma / \delta T, \mu_{{ }}$and $\alpha$, of -0.3 dyne $/(\mathrm{cm} . \mathrm{K}), 5 \times 10^{-2} \mathrm{~g} /(\mathrm{cm} . \mathrm{s})$ and $5 \times 10^{-2} \mathrm{~cm}^{2} / \mathrm{s}$ respectively [26], $\Delta T$ of $650 \mathrm{~K}$ and 2000 $\mathrm{K}$ for argon and helium respectively [19] and a characteristic length $L$ of $4.4 \mathrm{~mm}$ and $4.8 \mathrm{~mm}$ for argon and helium respectively as measured in this study, the Marangoni number can be determined. Therefore, since the temperature coefficient of surface tension is negative, the flow is radially outwards on the pool surface and a Marangoni number of $3.43 \times 10^{4}$ for argon and $1.15 \times 10^{5}$ for helium calculated; this implies that the flow becomes stronger [27], i.e. the flow velocity increases. The Marangoni number for argon is in line with those presented elsewhere [26].

Considering the forces evaluated, it can be inferred that the flow vectors are opposite in direction to that of argon as stated by Kang et al. [2]. It was calculated that helium produced a greater 
plasma shear stress, buoyancy force and Marangoni convection, whereas argon produced a greater arc force and Lorentz force. This suggests that the liquid weld metal flow for helium will move radially outwards at the pool surface and return beneath the pool surface, and conversely when using argon the liquid weld metal will move vertically downwards and then radially outwards before returning nearer to the pool surface.

\section{Conclusions}

A piezoelectric pressure sensor has been implemented for the transient arc pressure measurement whilst using argon, helium, alternating shielding gases and GTAW-P, from which various forces acting on the liquid weld metal have been calculated.

The arc pressure results can be summarised as follow:

- Arc pressure for argon is considerably higher than that for helium.

- The arc pressure for alternating shielding gases is considerably higher than the steadystate values for argon and helium due to a pressure impulse at weld initiation.

- The transient arc pressure measurement during alternating shielding gases has been shown to be considerably different from the previous theoretical assumptions:

- Due to the length of time each gas is supplied $(0.25 \mathrm{~s})$, the arc pressure is always in the arc initiation phase, hence there is no steady-state pressure for either gas.

- The 'spikes' between steady-state pressures do not exist.

- Whilst the transient pressure measurement of GTAW-P has been shown to be similar in form to that produced during alternating shielding gases. However, arc pressures for alternating shielding gases are comparable to those at arc initiation, whilst GTAW-P produces arc pressures comparable to the steady-state values.

The arc force results can be summarised as follow:

- Helium produces a greater plasma shear stress than argon, $\sim 240 \mathrm{~N} / \mathrm{m}^{2}$ and $\sim 80 \mathrm{~N} / \mathrm{m}^{2}$ respectively, and occurs approximately $1 \mathrm{~mm}$ from the arc centreline.

- Argon produces a greater arc force than helium, $\sim 1800$ dyne and $\sim 1140$ dyne respectively.

- Argon produces a greater Lorentz force than helium, $5.08 * 10^{5} \mathrm{~N} / \mathrm{m}^{3}$ and $3.25 * 10^{5} \mathrm{~N} / \mathrm{m}^{3}$ respectively. The Lorentz force distribution showed that argon had a greater 'core' $(<1.25$ $\mathrm{mm})$ Lorentz force, while helium produced a greater 'outer core' $(>1.25 \mathrm{~mm})$ Lorentz force.

- It was estimated that helium produces a buoyancy force approximately three times greater than argon due to the higher weld pool temperature.

- The calculated Marangoni number for helium is greater than argon, $1.15^{*} 10^{5}$ and $3.43 * 10^{4}$ respectively. This indicates that the Marangoni convection is stronger for helium than argon.

Considering the forces acting on the liquid weld metal, it can be inferred that the flow vectors for helium are opposite in direction to that produced by argon, creating a dynamic action within the weld pool when using alternating shielding gases. This effect would not be present during the GTAW-P process as all the flow would be in the same direction, however the magnitude of the forces would vary causing a 'jerking' motion within the liquid weld metal. 


\section{Acknowledgements}

The authors would like to acknowledge the funding provided by BAE Systems Surface Ships Limited, which has made this research possible.

In addition, the authors would like to acknowledge the conference funding provided by the Scottish Association for Metals and Regula Systems AB.

\section{References}

1. Y.H. Chang: 'Improve GMAW and GTAW with alternating shielding gases', Welding Journal, 2006, 85(2), 41-43.

2. B.Y. Kang, Y.K.D.V. Prasad, M.J., Kang, K.J., Kim and I.S. Kim: 'Characteristics of alternate supply of shielding gases in aluminium GMA welding', Journal of Materials Processing Technology, 2009, 209(2009), 4716-4721.

3. S.W. Campbell, A.M., Galloway and N.A. McPherson: Techno-economic evaluation on the effects of alternating shielding gases for advanced joining processes. Proceedings of the Institution of Mechanical Engineers, Part B: Journal of Engineering Manufacture, 2011, 225(10), 1863-1872.

4. S.W. Campbell, A.M. Galloway and N.A. McPherson: 'Evaluation of gas metal arc welding with alternating shielding gases for use on AA6082T6', Proceedings of the Institution of Mechanical Engineers, Part B: Journal of Engineering Manufacture, 2012, 226(6), 992-1000.

5. B.Y. Kang, Y.K.D.V. Prasad, M.J., Kang, K.J. Kim and I.S. Kim: 'The effect of alternate supply of shielding gases in austenite stainless steel GTA welding', Journal of Materials Processing Technology, 2009, 209(2009), 4722-4727.

6. S.W. Campbell, A.M., Galloway and N.A. McPherson: 'Artificial neural network prediction of weld geometry performed using GMAW with alternating shielding gases', Welding Journal, 2012, 91(6), 174-181.

7. D. Fan, M. Ushio and F. Matsuda: 'Numerical computation of arc pressure distribution', Transactions of JWRI, 1986, 15(1), 1-5.

8. R.T.C. Choo, J. Szekely and R.C. Westhoff: 'On the calculation of the free surface temperature of gas-tungsten-arc weld pools from first principles: part 1. modeling the welding arc', Metallurgical Transactions B, 1992, 23B, 357-369.

9. D.-S. Oh, Y.-S. Kim and S.-M. Cho: 'Derivation of current density distribution by arc pressure measurement in GTA welding' Science and Technology of Welding and Joining, 2005, 10(4), 442-446.

10. M. L. Lin and T.W. Eager: 'Pressures produced by gas tungsten arcs', Metallurgical Transactions B, 1986, 17B, 601-607.

11. H.G. Fan and Y.W. Shi: 'Numerical simulation of the arc pressure in gas tungsten arc welding', Journal of Materials Processing Technology, 1996, 61(1996), 302-308.

12. S.Y. Lee and S.J. Na: 'Analysis of TIG welding using boundary-fitted coordinates', Proceedings of the Institution of Mechanical Engineers, Part B: Journal of Engineering Manufacture, 1995, 209, 153-164.

13. H.-S. Ham, D.-S. Oh and S.-M. Cho: 'Measurement of arc pressure and shield gas pressure effect on surface of molten pool in TIG welding', Science and Technology of Welding and Joining, 2012, 17(7), 594-600. 
14. S.Y. Lee and S.J. Na: 'Analysis of TIG welding arc using boundary-fitted coordinates', Proceedings of the Institution of Mechanical Engineers, Part B: Journal of Engineering Manufacture, 1995, 209(2), 153-164.

15. J. Hu and H.L. Tsai: 'Heat and mass transfer in gas metal arc welding. Part 1: The arc', International Journal of Heat and Mass Transfer, 2007, 50(2007), 833-846.

16. T.D. Burleigh and T.W. Eagar: 'Measurement of the force exerted by a welding arc', Metallurgical Transactions A, 1982, 14A, 1223-1224.

17. M.L. Lin and T.W. Eagar: 'Pressures produced by gas tungsten arcs', Metallurgical Transactions B, 1986, 17B, 601-607.

18. S. Kou and Y.H. Wang: 'Weld pool convection and its effect', Welding Journal, 1986, 65(3), 63-70.

19. S. Kou and D.K. Sun: 'Fluid flow and weld penetration in stationary arc welds', Metallurgical Transactions A, 1985, 16A, 203-213.

20. G.M. Oreper, T.W. Eagar and J. Szekely: 'Convection in arc weld pools', Welding Journal, 1983, 62(11), 307-312.

21. A. Matsunawa, S. Yokoya and Y. Asako: 'Convection in weld pool and its effect on penetration shape in stationary arcs', Transactions of JWRI, 1987, 16(2), 229-236.

22. S.W. Campbell, A.M. Galloway and N.A. McPherson: 'Arc pressure and weld metal fluid flow whilst using alternating shielding gases - Part 1: Arc pressure measurement', Science and Technology of Welding and Joining, under review.

23. S.W. Campbell, A.M. Galloway and N.A. McPherson: 'Arc pressure and weld metal fluid flow whilst using alternating shielding gases - Part 2: Arc force determination', Science and Technology of Welding and Joining, under review.

24. A. Traidia and F. Roger: 'A computational investigation of different helium supplying methods for the improvement of GTA welding', Journal of Materials Processing Technology, 2011, 211(2011), 1553-1562.

25. F.H. Ley, S.W. Campbell, A.M. Galloway and N.A. McPherson: unpublished work, 2013.

26. C. Limmaneevichitr and S. Kou: 'Visualization of Marangoni convection in simulated weld pools', Welding Journal, 2000, 79(5), 126-135.

27. S. Kou, C. Limmaneevichitr and P.S. Wei: 'Oscillatory Marangoni flow: a fundamental study by conduction-mode laser spot welding', Welding Journal, 2011, 90(12), 229-240. 